\title{
Simulation of Dynamic Thermal Behaviour for Housing in Warm Climate: The Case of Thermal Mass in Lightweight Envelopes
}

\author{
Chiara Tonelli ${ }^{*}$ and Ilaria Montella ${ }^{\#}$
}

Department of Architecture, Roma Tre University, Largo Giovanni Battista Marzi, 10, Rome, Italy

\begin{abstract}
Comparison between simulation results and measured performances is usually an open scientific problem, crucial to achieving the goal of NZEB performance.

This paper addresses this issue in relation to residential buildings, using as a case study "RhOME for denCity", the housing prototype developed by Roma TRE University and winner of Solar Decathlon Europe 2014

In a Mediterranean climate, the use of the mass combined with natural cross ventilation to control the indoor microclimate can be very effective in reducing HVAC use. Therefore, a "massive layer" was introduced in the inner surface of the envelope to not only contribute to the envelope transmittance value and the shifting phase of the thermal waves, but also as a thermal shock absorber to adjust the internal temperature, in both summer and winter.

This experimental envelope was tested over two weeks during the competition in Versailles. Although prototype thermal behaviour was monitored only during the competition, and not over an extended period, initial results provide information on how to size the thermal mass contribution for indoor comfort. In-depth simulation through TRNSYS was run prior to the construction phase. This paper presents the comparison between monitored performance and simulations in order to measure the amount of mass needed to obtain a numerical improvement in indoor comfort performance.
\end{abstract}

Keywords: Thermal mass contribution, Energy performance in Mediterranean Climate, Dynamic thermal simulation, Thermal mass in lightweight envelope, building performance comparison.

\section{INTRODUCTION}

\section{The Solar Decathlon Competition}

The Solar Decathlon international competition was established by the United States Department of Energy in 2002. It involves 20 multidisciplinary teams selected internationally and led by universities. Teams are required to design, engineer, build and maintain zeroenergy residential prototypes.

The competition originally targeted single-family homes, built on a shared site to form a fully functional suburban "solar village". In the 2014 edition, the competition moved towards a more urban and local approach, asking teams to develop and build modules to densify urban settlements in their country of origin.

The Solar Decathlon is unique in that a full set of sensors is installed in every competing home and are all connected to a centralized data-logger, transmitting real-time performance (comfort and energy balance) data over the web. Every team is required to simulate the tasks of daily home use, according to a Competition Calendar that establishes what is to be accomplished daily, leaving it up to the teams to decide how and when to combine these activities, such as laundry,

*Address correspondence to this author at the Department of Architecture, Roma Tre University, Largo Giovanni Battista Marzi, 10, Rome, Italy; Tel: +393358432560; E-mail: chiara.tonelli@uniroma3.it

\#Co-Author E-mail: ilariamontella@hotmail.com showers and cooking. Therefore, user behaviour becomes one of the parameters influencing the result of the performance, and therefore of the competition.

The Solar Decathlon also always emphasizes ease and speed of assembly and disassembly, as well as economical sustainability and affordability. The final result of the competition is combination of measured performance contests (energy balance, comfort conditions, house functioning) and juried contests. The results of measured contests will be used in this paper, balancing them with parallel measurements taken internally by the team.

\section{The Italian Submission}

Roma TRE is the sole Italian University ever admitted to the Solar Decathlon. It was selected for participation in the 2012 edition with its prototype called "MED in Italy", fast-assembly lightweight energy efficient housing tailored to the Mediterranean climate, awarded $3^{\text {rd }}$ prize, and again in 2014, with its prototype called "RhOME", awarded $1^{\text {st }}$ prize (Figure 1).

The team presented a prototype of an apartment in advanced but affordable social housing called RhOME, namely "a home for Rome", aiming to recover archaeological monumental areas in the city's suburbs, which are currently occupied by spontaneous informal settlements. Two of the main points of the competition rules ask to emphasizes ease and speed of assembly 


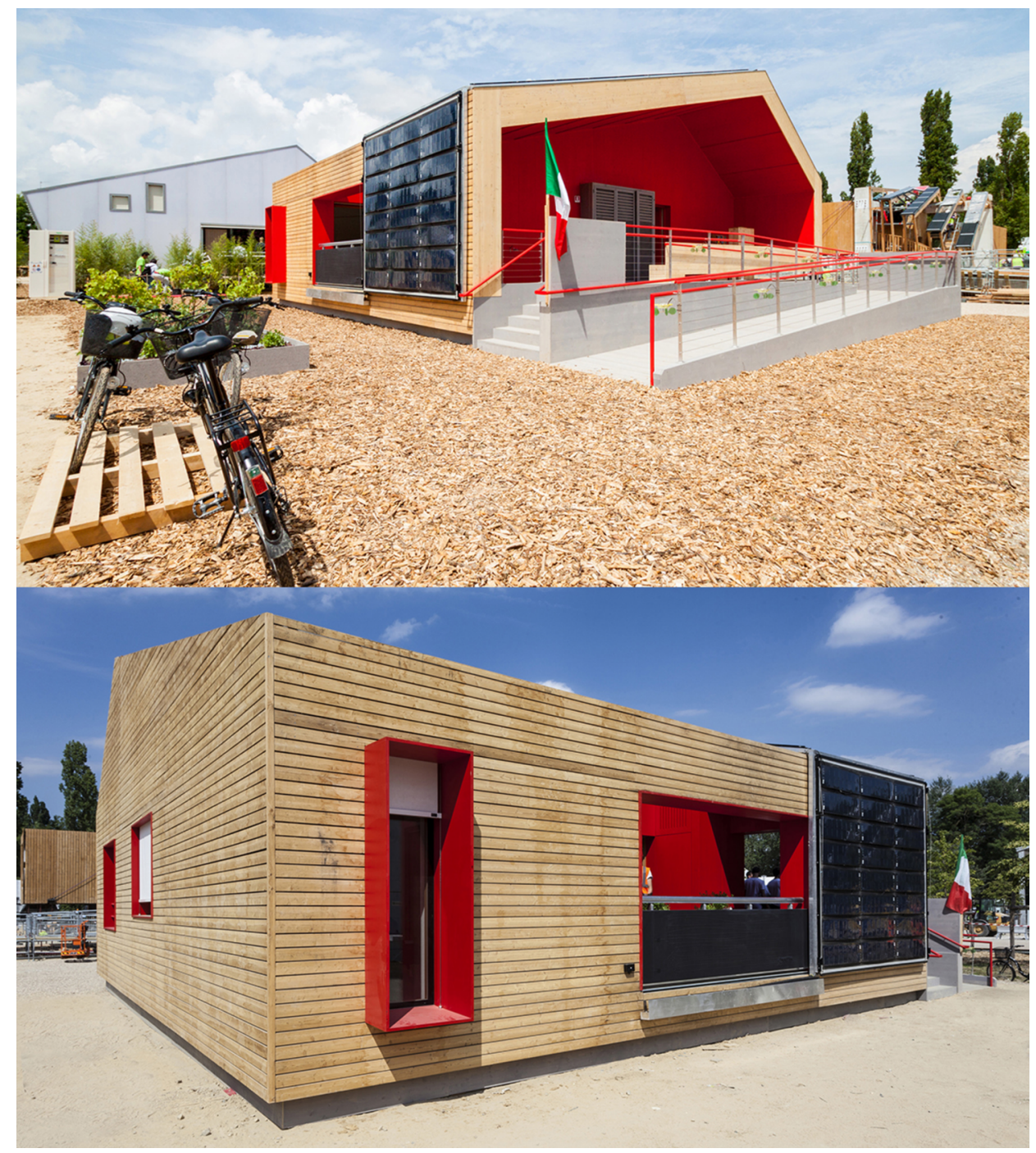

Figure 1: South and north facades. The PV-shading screen is visible on the south side.

and disassembly and to design for the climatic characteristic of country of origin. For this reason we selected a timber prefabricated construction system and we added sand in the inside layer of the envelope as thermal mass useful in Mediterranean climate.

\section{MATERIALS AND METHODS}

\section{The Bioclimatic Behaviour of the Housing Prototype: The Loggia as Main Feature of the Apartment Layout}

Rome has a Mediterranean humid temperate climate and therefore, generally comfortable temperatures in spring and autumn. The summer is generally hot, humid and with the potential for drought and the winter is mild and rainy. Starting from these considerations, the project aims to exploit the positive features of the climate and to defend interior comfort conditions from its most negative characteristics. The main feature around which the entire apartment layout is organized is the "loggia", an element from the Mediterranean tradition.

The loggias are designed for "bioclimatic" buildings with optimal orientation, according to the urban site location and for more internal flexibility. This objective is reached using a "U" or "L" shape for the glass walls surrounding every loggia, providing dual or triple exposure to solar radiation, with at least one of the windows facing south, regardless of the building's orientation at the urban level (Figure 2).

Each apartment features two loggias, with opposite orientations to optimize natural ventilation and cooling. Loggias also house production devices: a "thermodynamic balustrade", providing domestic hot water through a small heat pump, and a "PV shading screen", a lightweight sliding textile, hosting a photovoltaic field available to every apartment as a 

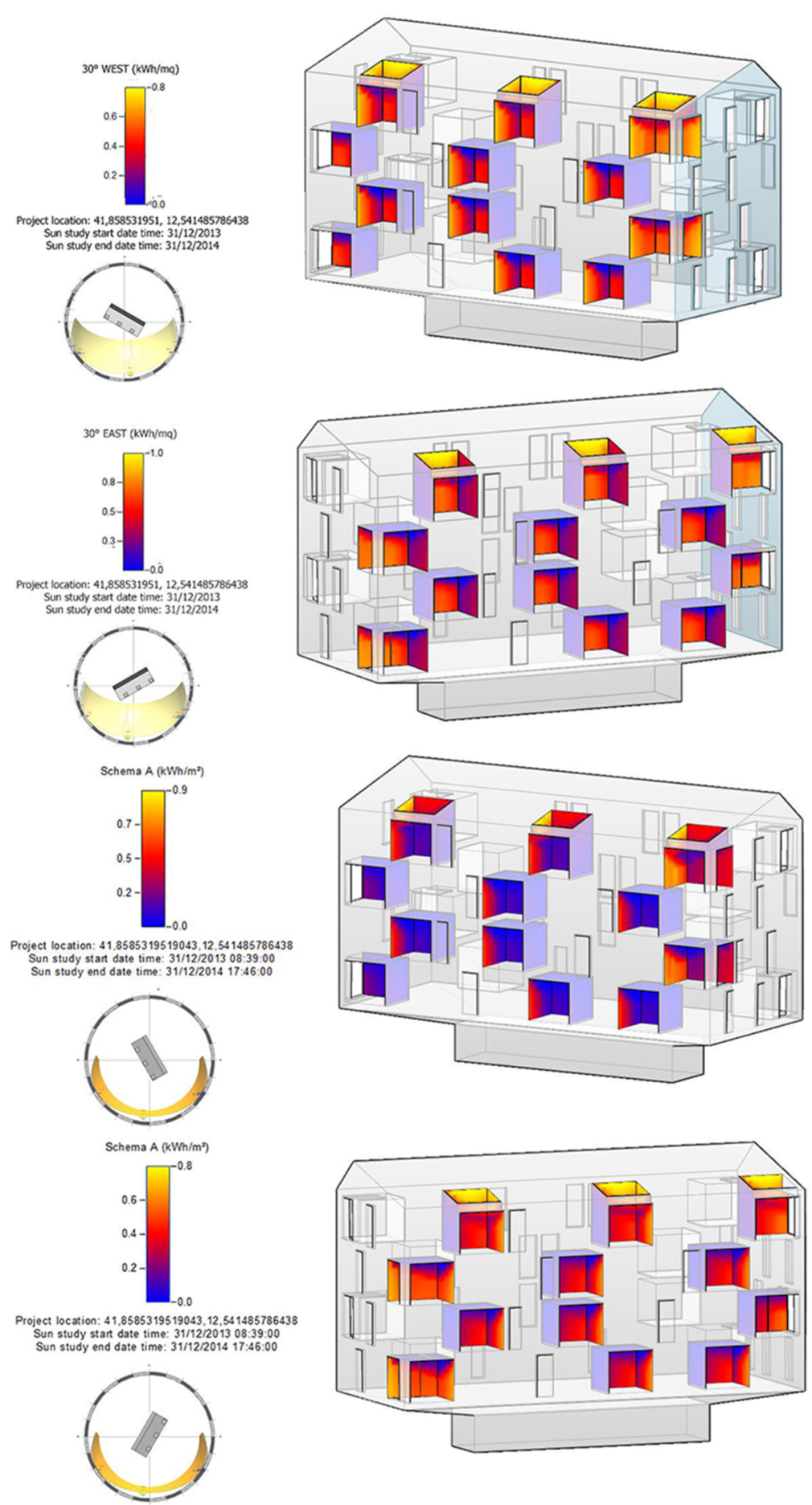

Figure 2: Simulation (Autodesk Vasari) of solar radiation for different multi-storey building orientations. One of the glazed surface of the loggia always faces south.

primary energy source for daily tasks (washing machine, etc.) (Figure 1). This direct connection is tailored to the PV surface for the exact number of apartments in multi-storey buildings. Great attention was also paid to the design of the exterior walls, featuring a low-density insulation system integrated in the timber platform frame and an outer layer with highdensity panels to eliminate thermal bridges. The insulation system is completed by a ventilated façade that helps reduce heat loads in summer caused by solar radiation.

\section{The Use of Thermal Mass in Combination with a Passive Cooling System}

The focus of the thermal strategy of the prototype was inspired by the bioclimatic diagram developed by 


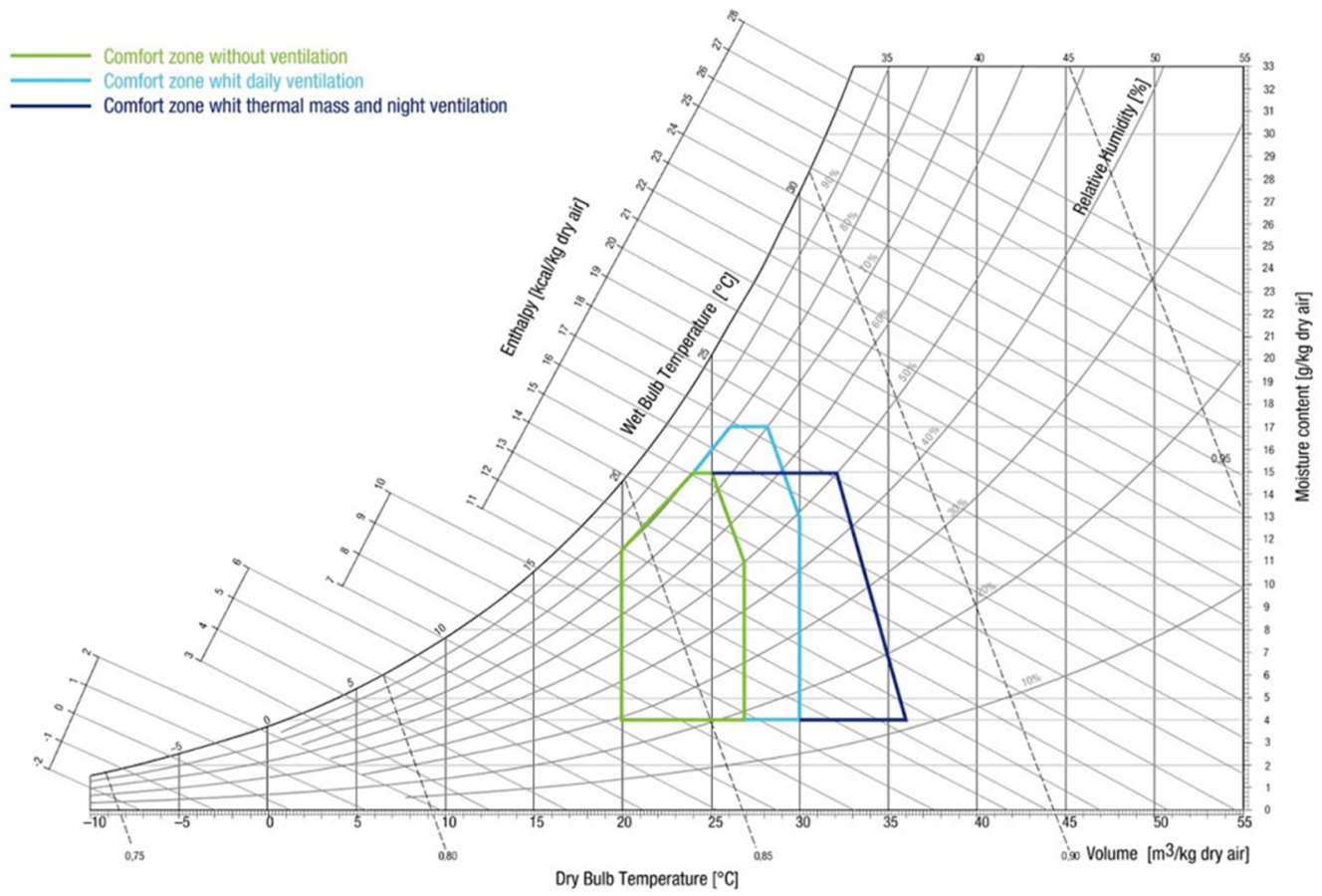

Figure 3: Bioclimatic diagram, highlighting the comfort zone (Baruch Givoni 1976).

Baruch Givoni [1] in 1976 (see Figure 3). The strategy is based on the idea that the use of passive cooling [2], can extend the interior comfort zone during summer [3], as shown on the ASHRAE psychrometric diagram.

In the climate of Rome, with high summer temperatures and mild winter ones [4], it is more important to provide protection from the summer heat than from the winter cold.
So, for this reason, and in order to use the benefits of the thermal mass, sand has been inserted in the inner layer of the envelope. The sand acts as a thermal shock absorber [5] to adjust the internal temperature, both in summer and winter [6] (Figure 4). During winter months, the sandabsorbs the thermal calories produced by solar gains and internal loads during the day and releases them at night. In summer, this thermal mass can attenuate heat peaks, and, thanks to

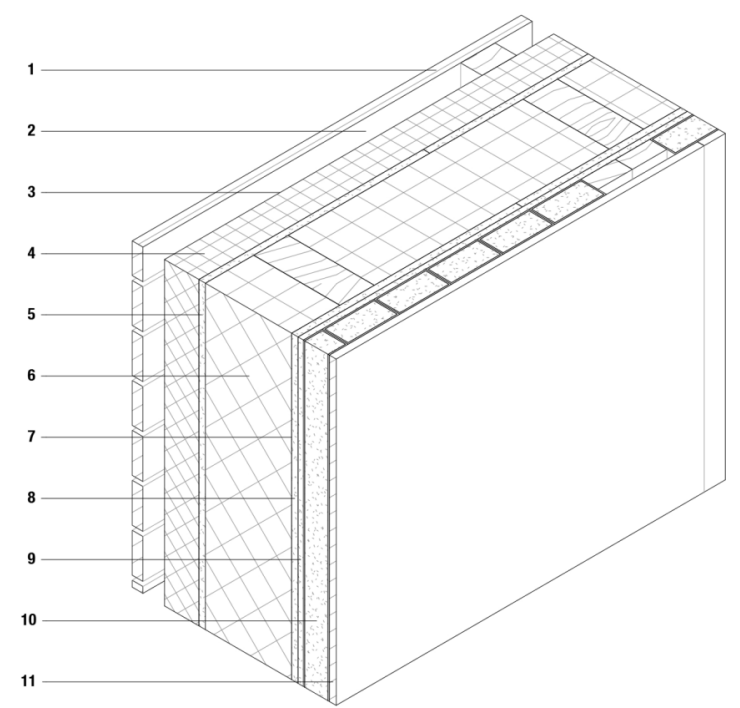

Figure 4: Mass Platform frame wall: layers listed from the outside to the inside.1. Wood finishing - Larch; 2 . Ventilated air cavity + spruce timber; 3 . Stamisol Color Red; 4. High density fiber wood; 5 . Fibergypsum; 6 . Low density fiber wood + spruce timber (mullions); 7. Breathable sheet; 8. Fibergypsum; 9. Gypsum board; 10. Wet sand + alluminium profiles + spruce timber (mullions); 11. Wood finishing - Spruce. 
natural cross ventilation, the temperature, heated during the day, can be cooled during the night $[7$ and 8]. At the same time, a thick insulation layer prevents overheating of the walls themselves and of the internal air. In this way, the comfort zone can be extended based on air velocity, humidity and inner temperature.

The mass contributes to the radiation effect [9] that provides users better comfort compared to lightweight envelopes and could be very effective in reducing HVAC use (Figures 5, 6).

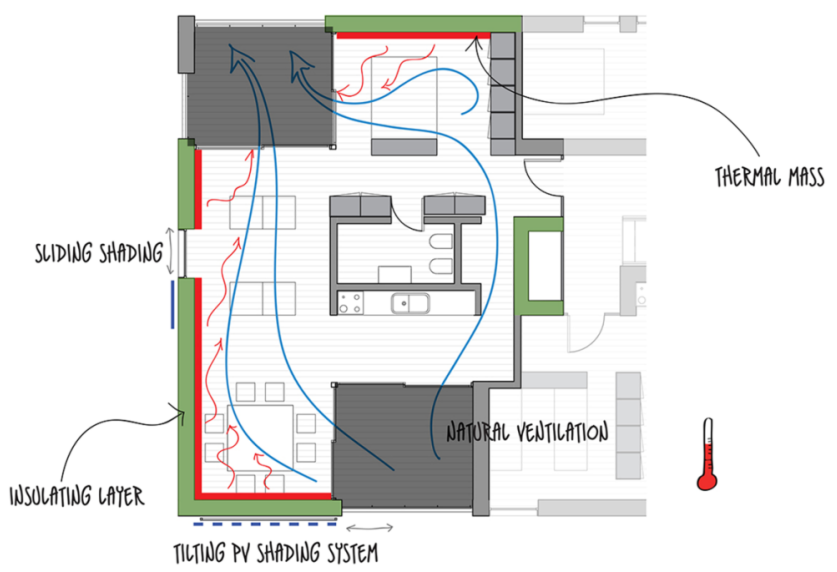

Figure 5: Housing prototype plan: the two loggias in grey and the position of the mass in red.

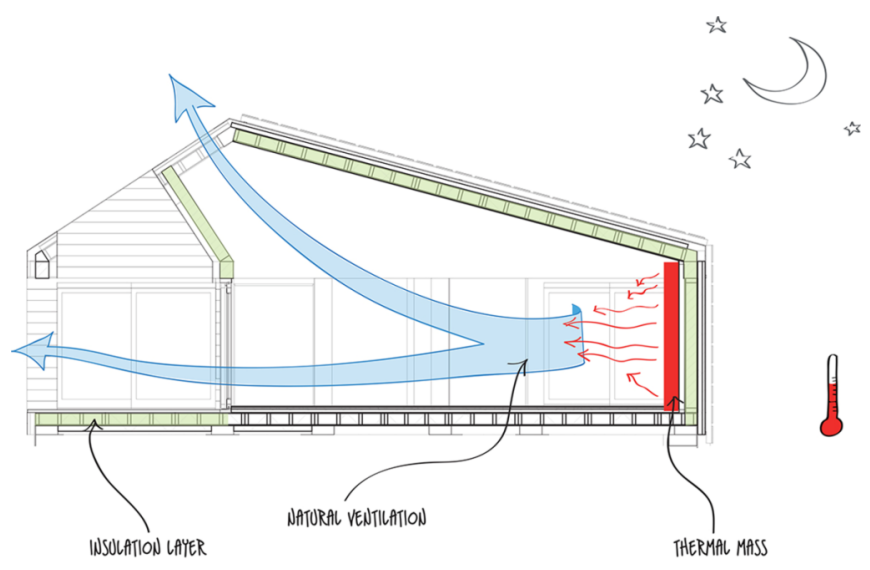

Figure 6: Housing prototype section.

During the competition, the prototype monitored for performance faced north, and the two loggias were oriented north and south. The northern ceiling window provided an efficient "chimney effect" improving cross ventilation and house cooling.

\section{Simulation}

The prototypes developed by Roma TRE University and built for the Solar Decathlon competitions are the experimental results of long-term research aimed to provide lightweight wooden buildings with thermal performance similar to the "heavy" and massive buildings inherited from the Mediterranean tradition [10]. Since the very beginning of the design process, the team also worked on integrating the thermal mass layer and on simulating how much this layer could actually influence the internal microclimate [11], and therefore reduce HVAC energy demands. Given this framework, our research has always balanced an intuitive strategy with regular attempts at validation, through simulations, tests and proofs of concept using built prototypes.

We evaluated the strategies designed and identified in our initial intuitions using different simulation software, each exploited for its specific characteristics.

In some cases, the results obtained from the simulations have confirmed design ideas, while in others, they have been an invaluable support to guide changes and optimize the project design. After an initial study and comparison of available platforms, like EnergyPlus $^{\mathrm{TM}}$ and TRNSYS, [12], the RhOME team chose TRNSYS 16 taking into account the results of comparative evaluation between them, reported in scientific source [13].

TRNSYS had used critically for its main potential as a simulator of systems.

One essential task in expanding the use of thermal mass [14] is to fully comprehend the data processing and algorithms of the application, and in particular how the software treats input data [15]. In the case of TRNSYS and RhOME, critical inputs were solar radiation and natural ventilation, both main factors in activating thermal mass.

Climate analysis data came from EPW weather files but, since that file does not include incidence angle of direct solar radiation, we calculated it using software based on geometrical models, specifically to the building's exact location and orientation: we calculated the overall radiation (direct and indirect) in Autodesk Ecotect, obtaining the percentage of exposure of glazed surfaces, and then transferred this information into TRNSYS as a forcing function, able to introduce the effects of shading based on building shape and with two different loggia configurations: open PV screen in winter, closed PV screen in summer.

In TRNSYS, the lack of a geometrical model means that solar radiation from glazed surfaces is distributed equally on all interior surfaces of the thermal zone, 
calculating average surface temperature and then distributing it as homogeneous to the entire thermal zone [16]. This is certainly an approximation of real behaviour.

Despite this limitation, we decided to proceed with the simulation, since one of the consequences of introducing thermal mass into a room is certainly the variation of its thermal capacity.

So, to evaluate the possible contribution of the interior mass, and its possible advantage in terms of energy savings, it is crucial to establish a relationship between the quantity of mass introduced and the related reduction of interior temperature in degrees [17]. This is possible only using software able to accurately simulate systems and ventilation, because by comparing two versions of the model, with and without mass, we can quantify the number of hours and amount of HVAC power that is reduced with the introduction of mass, and therefore potential savings.

We introduced the data of a room's thermal capacity for a certain amount of sand (expressed in cubic meters), using:

Cth $=H C^{*}\left(d^{*} V\right)$

Where:

Cth = Capacitance $(\mathrm{kJ} / \mathrm{K})$

$H C=$ Heat Capacity $(\mathrm{kJ} / \mathrm{kg} K)$ $\left(d^{*} V\right)=$ Weight $(\mathrm{kg})$

$d=$ Density $\left(\mathrm{m}^{3} / \mathrm{kg}\right)$

$V=$ Volume $\left(m^{3}\right)$

Employing the following values for the sand in the prototype:

density $=1054 \mathrm{~kg} / \mathrm{m}^{3}$

volume $=5.7 \mathrm{~m}^{3}$

weight $=6007.8$

heat capacity $=0.9 \mathrm{~kJ} / \mathrm{kgK}$

we obtained a capacitance of $5407.02 \mathrm{~kJ} / \mathrm{K}$.

The aim of the proofs was to determine whether mass actually affected internal air temperature, in combination with natural ventilation.

To verify our expected result, we performed thermal analysis with TRNSYS by creating two separate models: one with thermal mass and one without. We then compared the results of the two models to determine if and how mass and natural ventilation could improve passive interior comfort.

For this reason, the research team initially integrated just the sand layer in the model, and then introduced HVAC systems, namely a radiant system with an air-water heat pump and mechanical ventilation with a heat recovery unit. In this way, we obtained a passive and active simulation of the house.

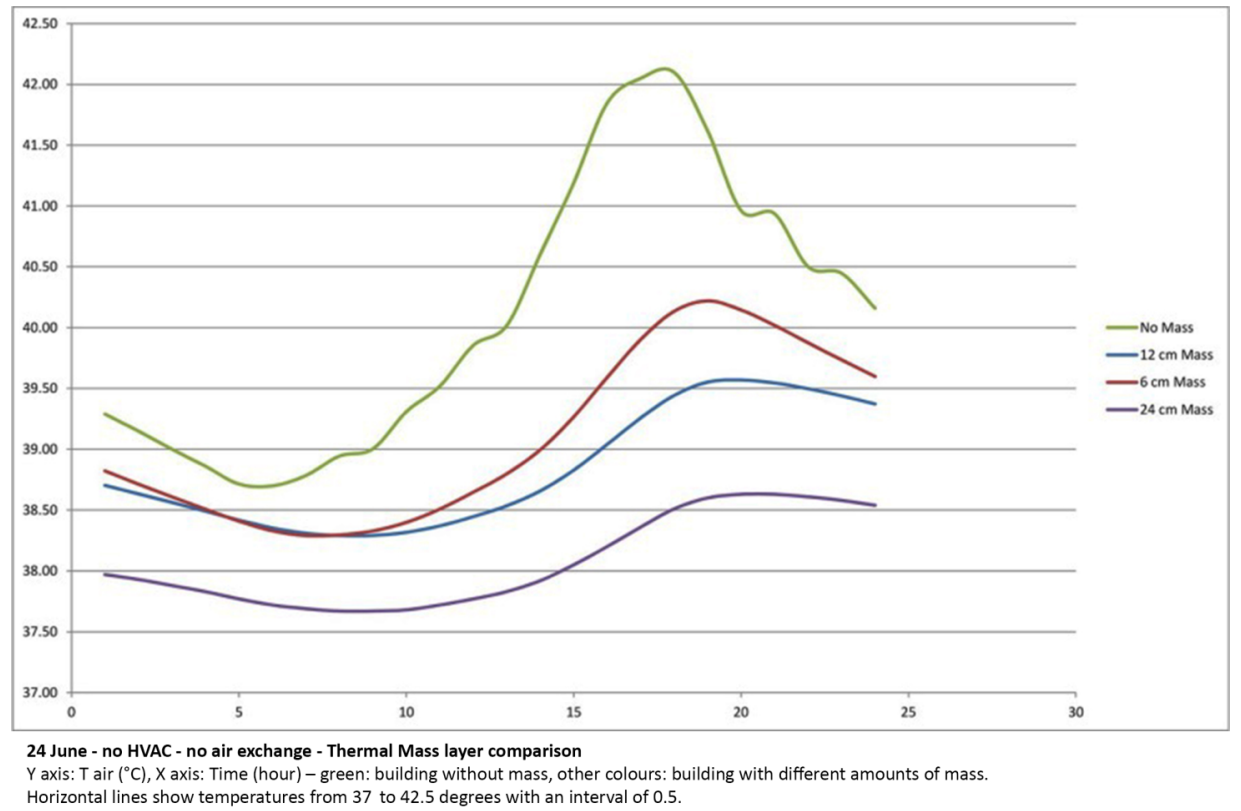

Figure 7: 24 June - no HVAC - no air exchange - Thermal Mass layer comparison - $\mathrm{Y}$ axis: $\mathrm{T}$ air $\left({ }^{\circ} \mathrm{C}\right), \mathrm{X}$ axis: Time (hour) green: building without mass, other colours: building with different amounts of mass. Horizontal lines show temperatures from 37 to 42.5 degrees with an interval of 0.5 . 


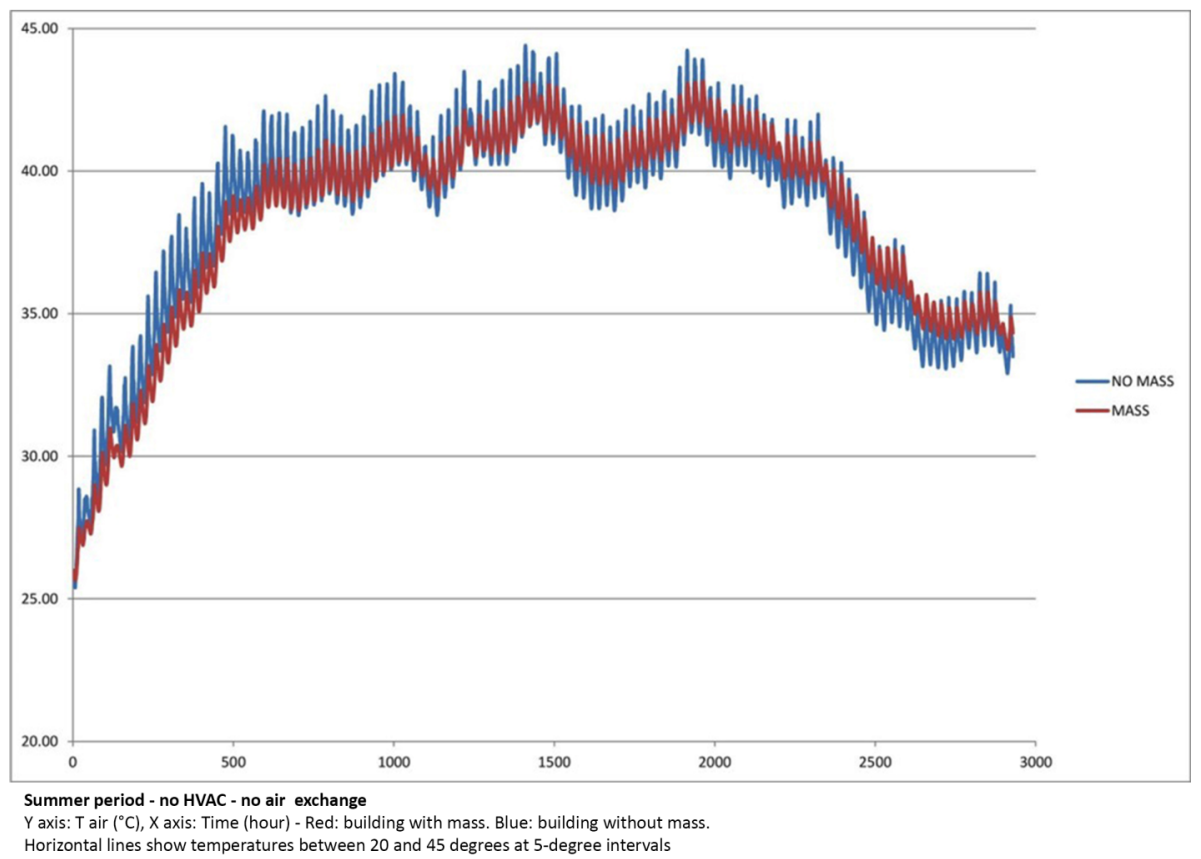

Figure 8: Summer period - no HVAC - no air exchange - $\mathrm{Y}$ axis: T air $\left({ }^{\circ} \mathrm{C}\right), \mathrm{X}$ axis: Time (hour) - Red: building with mass. Blue: building without mass. Horizontal lines show temperatures between 20 and 45 degrees at 5-degree intervals.

Prior to analyse interior temperature data, in order to evaluate if the model was built correctly and if the increase of mass affects internal room temperatures, we, have compared the results of three models with different sand layer thicknesses (and therefore different overall sand volumes): $24 \mathrm{~cm}, 12 \mathrm{~cm}$ and $6 \mathrm{~cm}$ (Figure $7)$. In the three cases, windows are closed and HVAC switched off in order to evaluate just the difference of heat capacity, without the contribution of the ventilation or air conditioning.

The objective of this was not to evaluate interior temperatures. Instead, we wanted to verify that the presence of the mass truly contributed to temperature change, and in particular, to "compressing" the temperature graph into a smaller range, avoiding extreme peaks.

The graph in Figure 8 shows that TRNSYS takes into account the behaviour of the mass in summer, even without the contribution of ventilation, and interior temperatures are reduced.

After realizing that the software did take into account the contribution of thermal mass, the team decided to add the contribution of ventilation to the model, still without HVAC (see Figure 9).

The simulation model takes into account an air change rate according to standard EN 15251:2007 [18].
To ensure air change and to avoid moisture, the regulation suggests rates between 0.5 and 0.7 spare parts, or more, for a $2.5 \mathrm{~m}$ high ceiling residence of air change.

In our simulation, considering a Mediterranean climate, we decided to use 1 spare part per hour.

According to an initial evaluation, the graph shows that the sand layer performs as expected in summer.

At this stage, the model is expanded and examined in detail, taking into account the results of two days, one in summer, one in winter, shown by graphs in Figures 10, 11 and 12. Comparison of the two curves (with and without mass) from the simulation shows that the thermal mass layer reduces temperature by approximately 2 degrees (Figure 13), but also helped to "compress" the temperature curve and reduce the temperature range. In summer, in particular, the contribution of mass helps to shift the temperature peak by approximately 3 hours, from $3 \mathrm{PM}$ to $6 \mathrm{PM}$, at a time of day when solar thermal loads are definitely lower. In winter, the contribution of mass also reduces temperature variations throughout the day. According to this, and to the premises at the beginning of this paragraph, the results of TRNSYS simulation show that the model has a potential effect of mass in a very insulated building.

In addition, for the competition the team had to make the prototype energy certification and the 


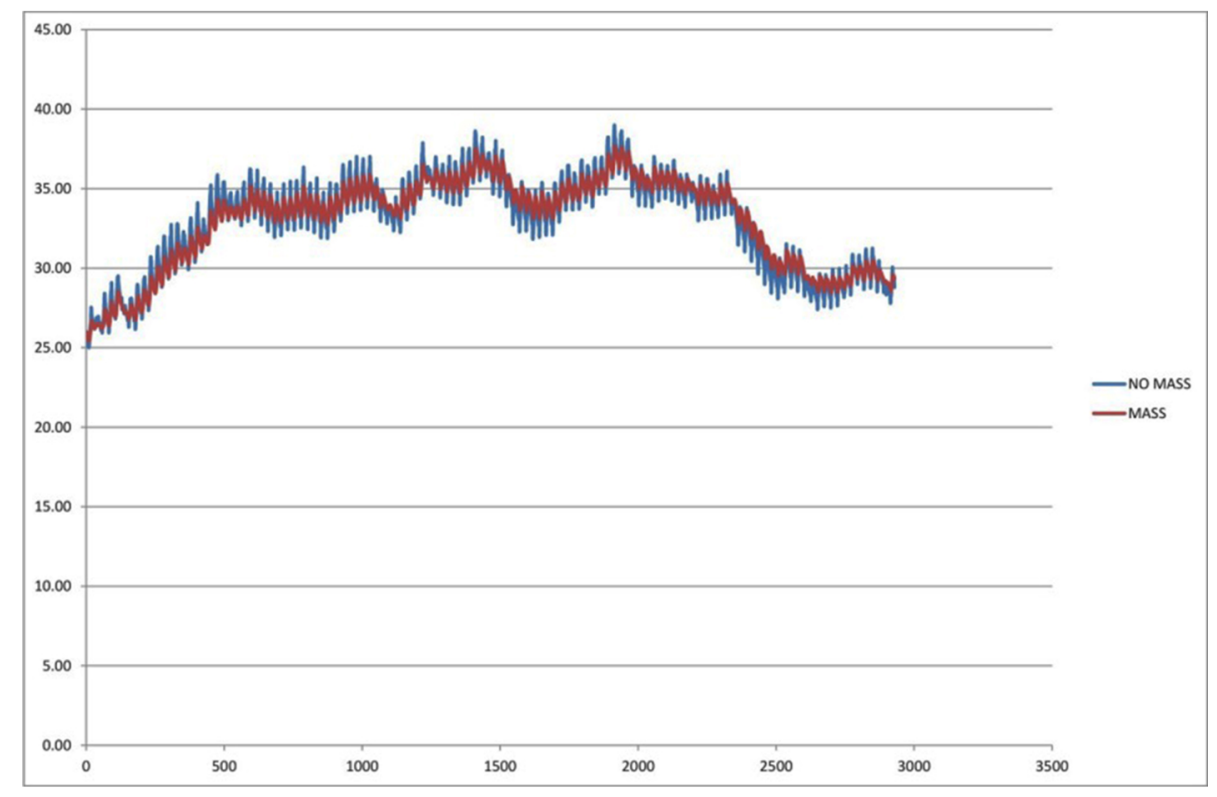

Summer period - no HVAC - 1 ach
$Y$ axis: T air ( ${ }^{\circ} \mathrm{C}$ ) $\mathrm{X}$ axis: Time (hour) - Red: building with mass. Blue: building without mass. Horizontal lines show temperatures between 0 and 45 degrees at 5 -degree intervals.

Figure 9: Summer period - no HVAC - 1 ach - $Y$ axis: $T$ air $\left({ }^{\circ} \mathrm{C}\right), \mathrm{X}$ axis: Time (hour) - Red: building with mass. Blue: building without mass. Horizontal lines show temperatures between 0 and 45 degrees at 5 -degree intervals.

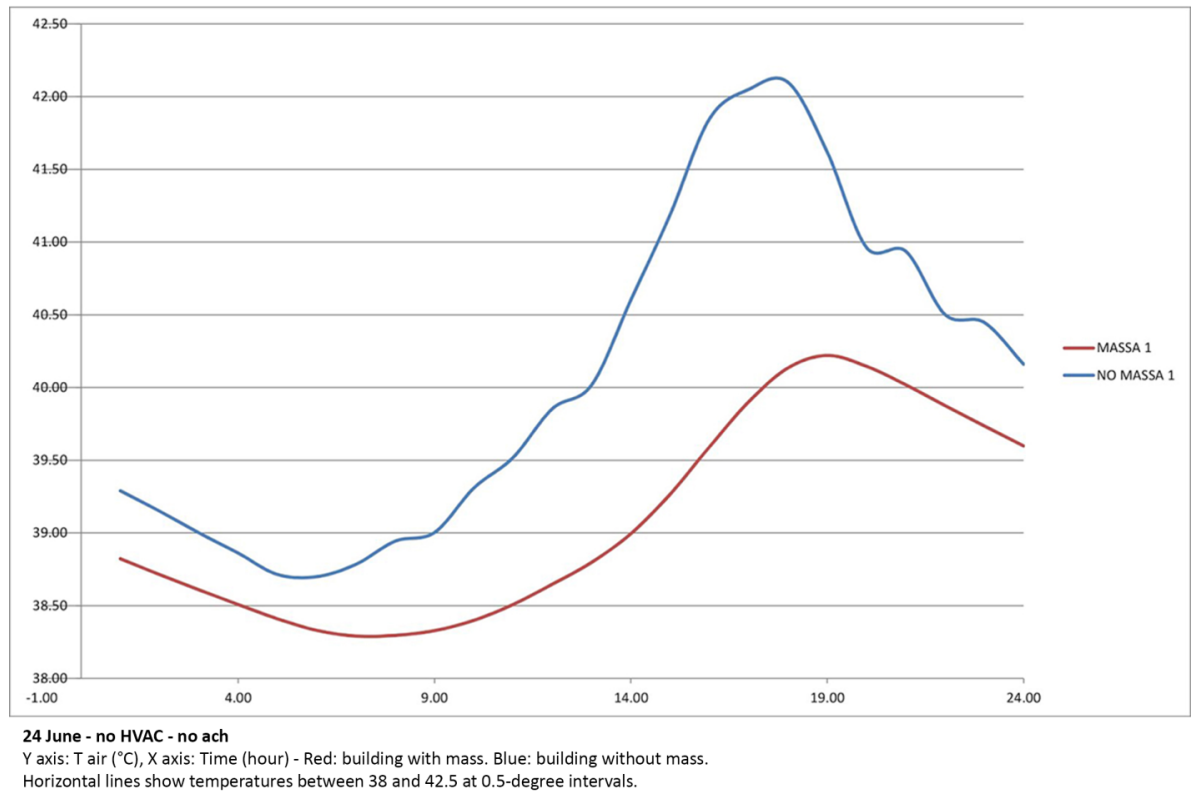

Figure 10: 24 June - no HVAC - no ach - Y axis: T air $\left({ }^{\circ} \mathrm{C}\right), \mathrm{X}$ axis: Time (hour) - Red: building with mass. Blue: building without mass. Horizontal lines show temperatures between 38 and 42.5 at 0.5 -degree intervals.

performance of the building envelope with the CasaClima protocol, using the steady-state calculation software prescribed and developed by the CasaClima Agency (Klimahaus), partner of this research. The tool, namely ProCasaClima, even if is only a steady-state calculation software, has been useful to evaluate how admittance, periodic transmittance, and thermal capacity were different for the presence of the thermal mass.
The team chose mainly natural materials for the stratigraphy of the envelope. We were looking for low environmental impact but also respect of parameters for periodical thermal transmittance, and superficial mass, included in Italian Law DPR 59/09. The values are:

- $\quad$ Periodical Thermal Transmittance

YIE $\left(\mathrm{W} / \mathrm{m}^{2} \mathrm{~K}\right)<0.12 \mathrm{~W} / \mathrm{m}^{2} \mathrm{~K}$ 


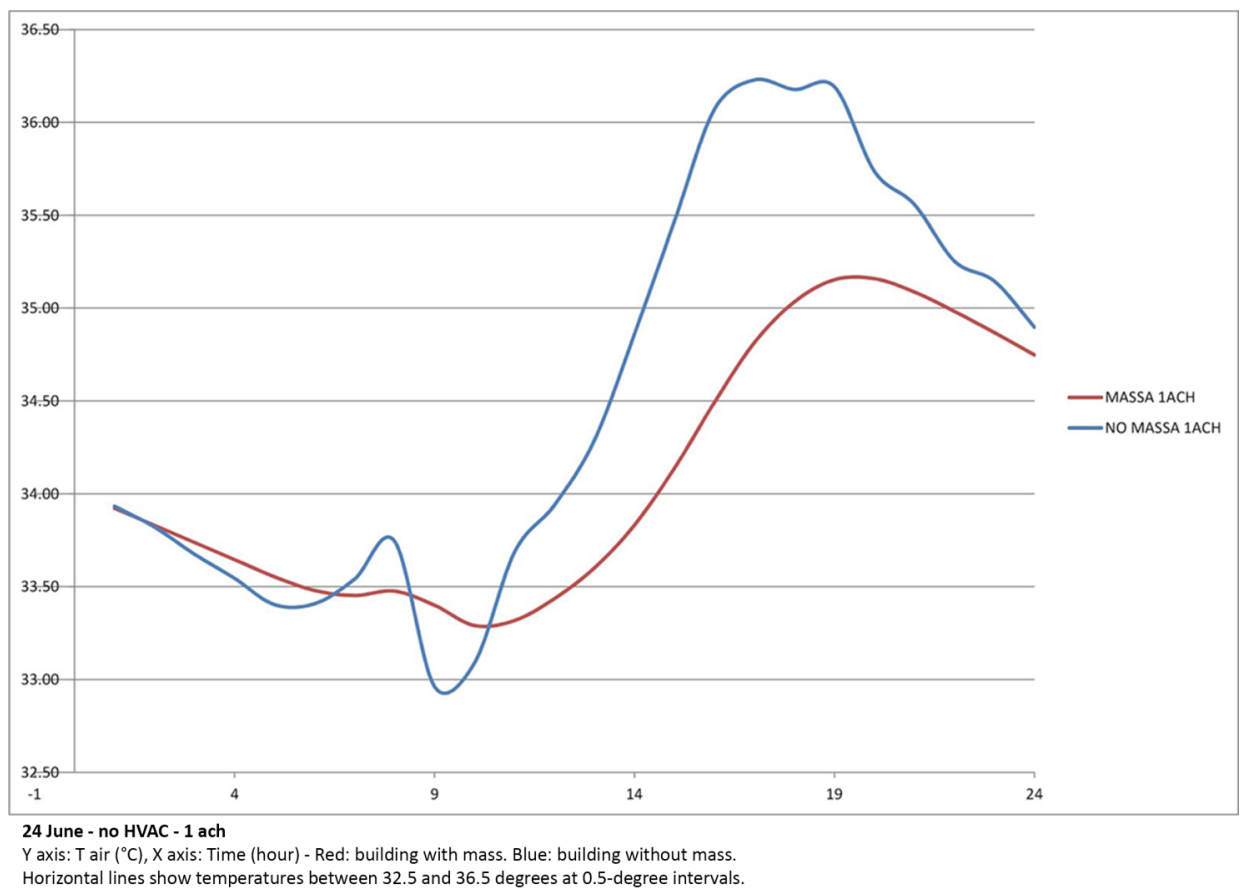

Figure 11: 24 June - no HVAC - 1 ach - $\mathrm{Y}$ axis: $\mathrm{T}$ air $\left({ }^{\circ} \mathrm{C}\right), \mathrm{X}$ axis: Time (hour) - Red: building with mass. Blue: building without mass. Horizontal lines show temperatures between 32.5 and 36.5 degrees at 0.5 -degree intervals.

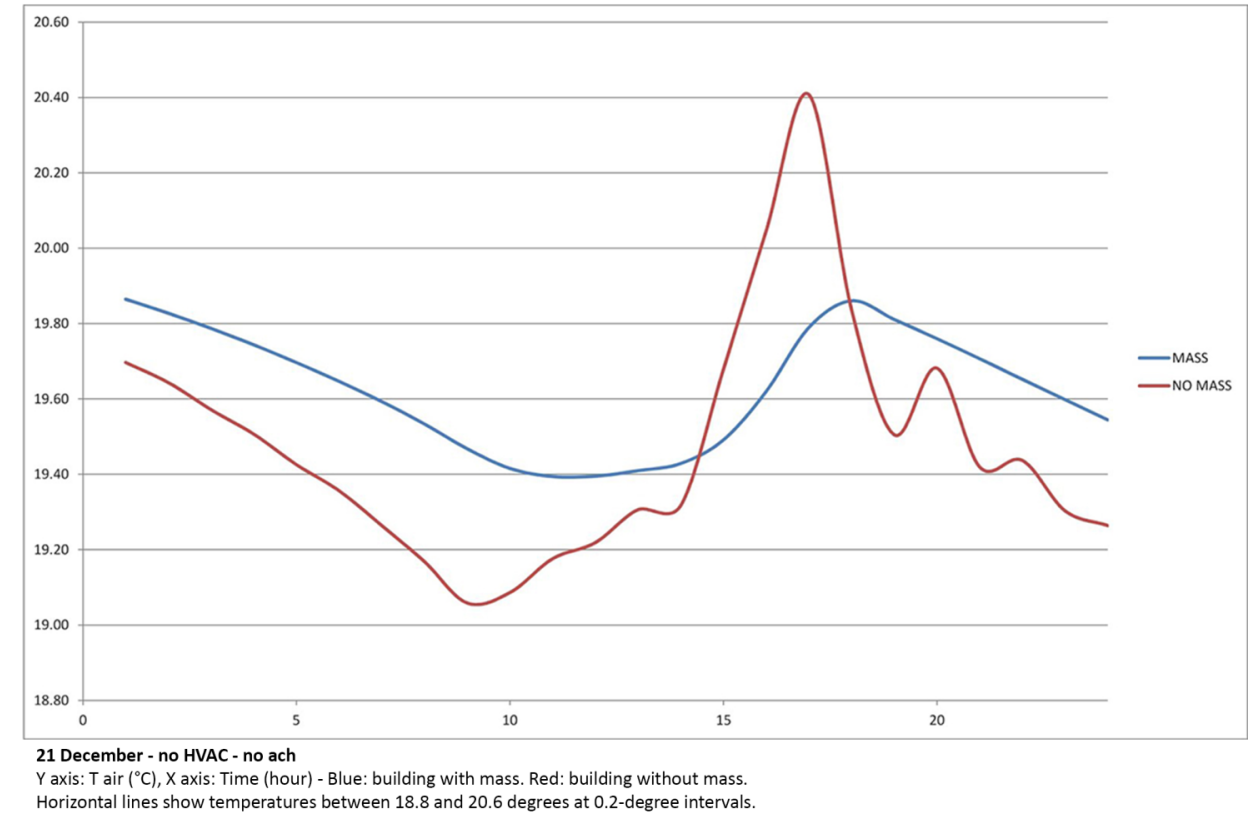

Figure 12: 21 December - no HVAC - no ach - $Y$ axis: T air $\left({ }^{\circ} \mathrm{C}\right), \mathrm{X}$ axis: Time (hour) - Blue: building with mass. Red: building without mass. Horizontal lines show temperatures between 18.8 and 20.6 degrees at 0.2-degree intervals.

- $\quad$ Superficial Mass Ms $\left(\mathrm{kg} / \mathrm{m}^{2}\right)>230 \mathrm{~kg} / \mathrm{m}^{2}$.

Actual values of the RhOME envelope, obtained from calculations are $\mathrm{YIE}=0.02 \mathrm{~W} / \mathrm{m}^{2} \mathrm{~K}$ and $\mathrm{Ms}=0.17$ $\mathrm{W} / \mathrm{m}^{2} \mathrm{~K}$.

Another significant value in the steady-state simulation is the difference between thermal capacity and admittance value in the two models, with and without sand. Specifically, as expected, the model with sand showed a higher internal thermal capacity (14 $\mathrm{Wh} / \mathrm{m}^{2} \mathrm{~K}$ ) compared to the model without sand (10 $\left.\mathrm{Wh} / \mathrm{m}^{2} \mathrm{~K}\right)$. At the same time, the admittance value is higher in the first model $\left(3.60 \mathrm{~W} / \mathrm{m}^{2} \mathrm{~K}\right.$ compared to 2.53 $\left.\mathrm{W} / \mathrm{m}^{2} \mathrm{~K}\right)$. 
Thermal mass comparison

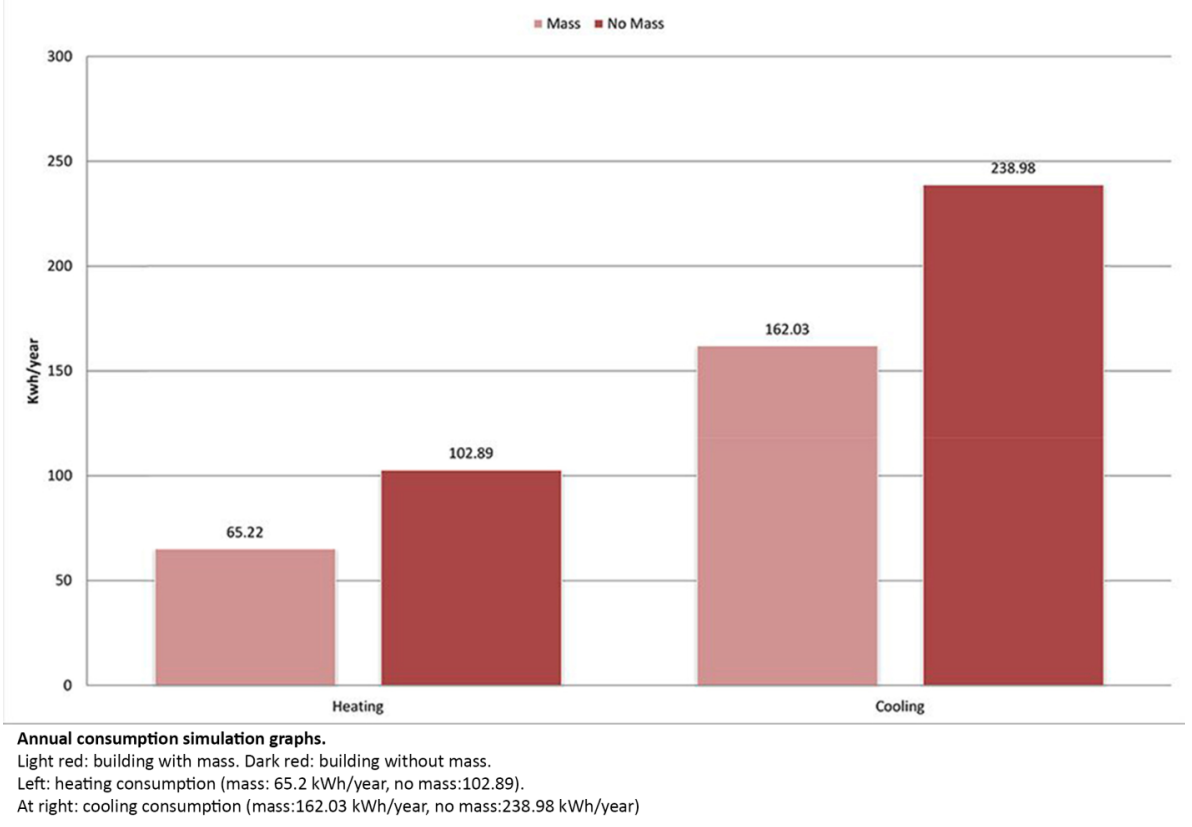

Figure 13: Annual consumption simulation graphs. Light red: building with mass. Dark red: building without mass. Left: heating consumption (mass: $65.2 \mathrm{kWh} / \mathrm{year}$, no mass:102.89 kWh/year). At right: cooling consumption (mass:162.03 kWh/year, no mass:238.98 kWh/year).

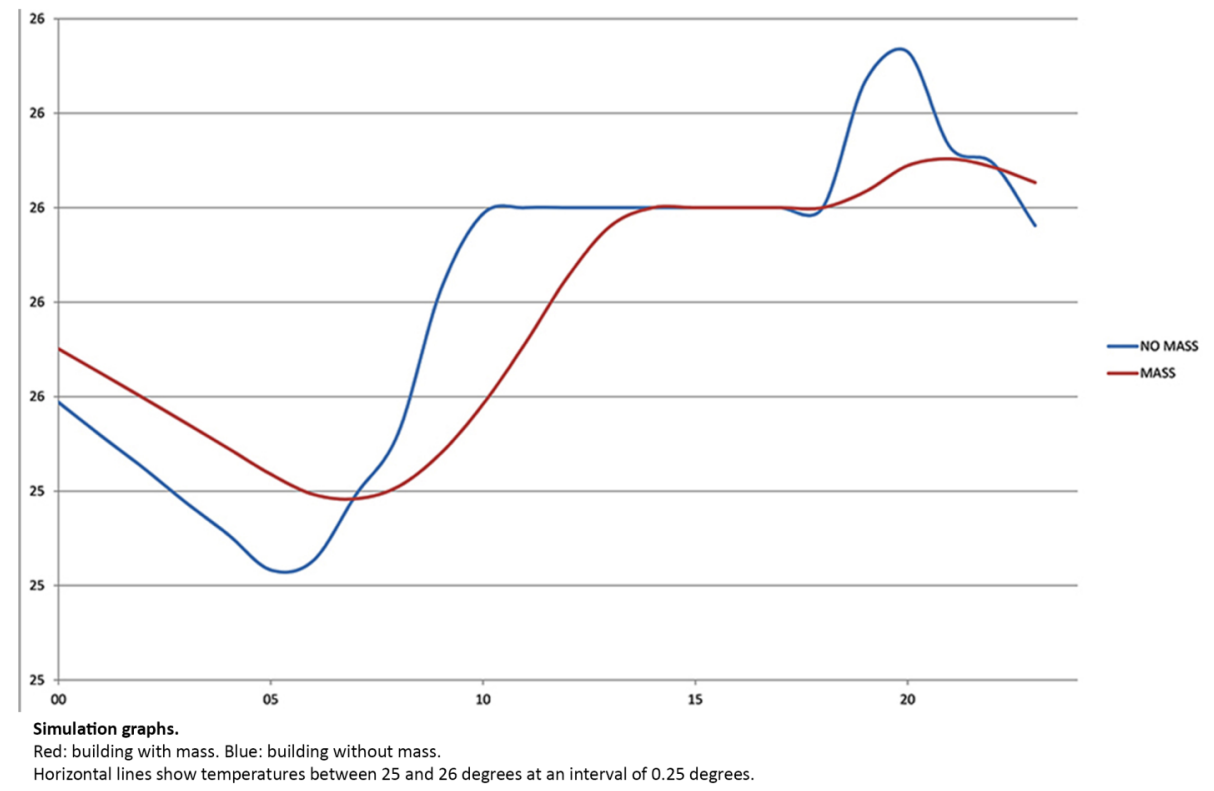

Figure 14: Simulation graphs. Red: building with mass. Blue: building without mass. Horizontal lines show temperatures between 25 and 26 degrees at an interval of 0.25 degrees.

\section{RESULTS}

\section{Climatic Chamber Tests: Validation, Discussion and Result Analysis}

The first validation of the digital simulation involved measurements on a physical mock-up in a climatic chamber. The team worked with the EURAC Institute in Bozen, Italy to validate the results of the mathematical models on the behaviour of the thermal mass layer, described above. Validation was done on a physical mock-up of a portion of the envelope. The Institute's climatic chamber was able to perform both dynamic and steady state conditions.

The test was conducted by positioning the wall portion $(1.7 \mathrm{~m} \times 1.7 \mathrm{~m} \times 0.459 \mathrm{~m})$ between two chambers, simulating exterior and interior climates. In 
the chamber, it is possible to switch from summer to winter, and the solar effect can be activated on the exterior surface.

Once the mock-up was set up properly, tests were conducted according to standard code EN 8990:1999. The test on the mock-up's thermal capacity followed the indications of standard code ASTM C1363.

The results of the first tests were compatible with the TRNSYS simulations. Although the prototype's thermal behaviour was monitored only during the competition and not yet for a long period, initial results can give some indication on how to size thermal mass contribution for indoor comfort. Additionally, more experiments should be conducted on the mock-up without the sand layer in order to evaluate the difference between the two.

\section{Competition Tests}

The second, digital simulation was validated through measurements taken in July 2014 during the Solar Decathlon competition in Versailles, France.

As stated above, the houses were fully functional during the two weeks of the competition: each team was required to perform tasks simulating daily life according to a Competition Calendar.

Data on energy consumption and comfort conditions were available through official measurements taken by the organization, as well as through internal measurements by a custom system developed by the team.

Therefore, for each competition day, data show daily energy balance and time and consumption from our internal monitoring system for every single activity performed, showing how good user behaviour was and its influence on results.

This a precious feature of the Solar Decathlon initiative, since it builds a detailed profile of users' real behaviour in the house.

It suggests the possibility to repeat simulations in TRNSYS replacing the generic user profile and adding the real temperatures monitored during the competition to the model. The difference between the ideal behaviour of the simulation and monitored data also had to address peculiarities due to the competition rules.
The interior daily set point, for instance, given by the organization was not a fixed value as in the simulation, where we used a fixed value of $26^{\circ} \mathrm{C}$, generally used in Italian codes.

Instead, the competition used a variable value, according to standard EN 15251. The average day's exterior temperature was determined by the following equation:

$T^{\circ} \mathrm{ea}=\left(T^{\circ} \mathrm{ed}-1+0.8 T^{\circ} \mathrm{ed}-2+0.6 T^{\circ} \mathrm{ed}-3+0.5 T^{\circ} \mathrm{ed}-4\right.$

$\left.+0.4 T^{\circ} \mathrm{ed}-5+0.3 T^{\circ} \mathrm{ed}-6+0.2 T^{\circ} \mathrm{ed}-7\right) / 3.8$

Where:

$T^{\circ}$ ea $=$ day's average exterior temperature

$T^{\circ} e d-x=$ daily average exterior temperatures of previous days

Then, the available points range was calculated every day by the following expression:

$$
T^{\circ} i \min <T^{\circ} i<T^{\circ} i \max
$$

Where:

$T^{\circ} i=$ interior operative temperature

$T^{\circ} i \mathrm{~min}=$ minimum interior operative temperature

$T^{\circ} i \max =$ maximum interior operative temperature

$T^{\circ} i \min$ and the $T^{\circ} i$ max were given by the following expressions:

$T^{\circ} \mathrm{i} \min =0.33 T^{\circ} \mathrm{ea}+18.8-1$

$T^{\circ} i \max =0.33 T^{\circ} \mathrm{ea}+18.8+1$

Reduced points were earned if the indoor temperature was maintained within a range of $2^{\circ} \mathrm{C}$ above or below the full points range.

Because the competition was held in summer, we thought it interesting to simulate with TRNSYS the conditions the house experienced during the two days $\left(8^{\text {th }}\right.$ and $9^{\text {th }}$ July) called "Passive days" of the competition, where HVAC had to be turned off, except for Mechanical Ventilation. We used the following assumptions in the simulation:

- Initial value: $25^{\circ} \mathrm{C}$ temp, with $50 \% \mathrm{RH}$

- Set point for the heat recovery system: $25^{\circ}$

- $\quad 1.5$ ach from 8:00 PM to 7:00 AM

- $\quad 5 \mathrm{~W} / \mathrm{m}^{2}$ appliance internal gains

- Two people "seated at rest" for 24 hours 


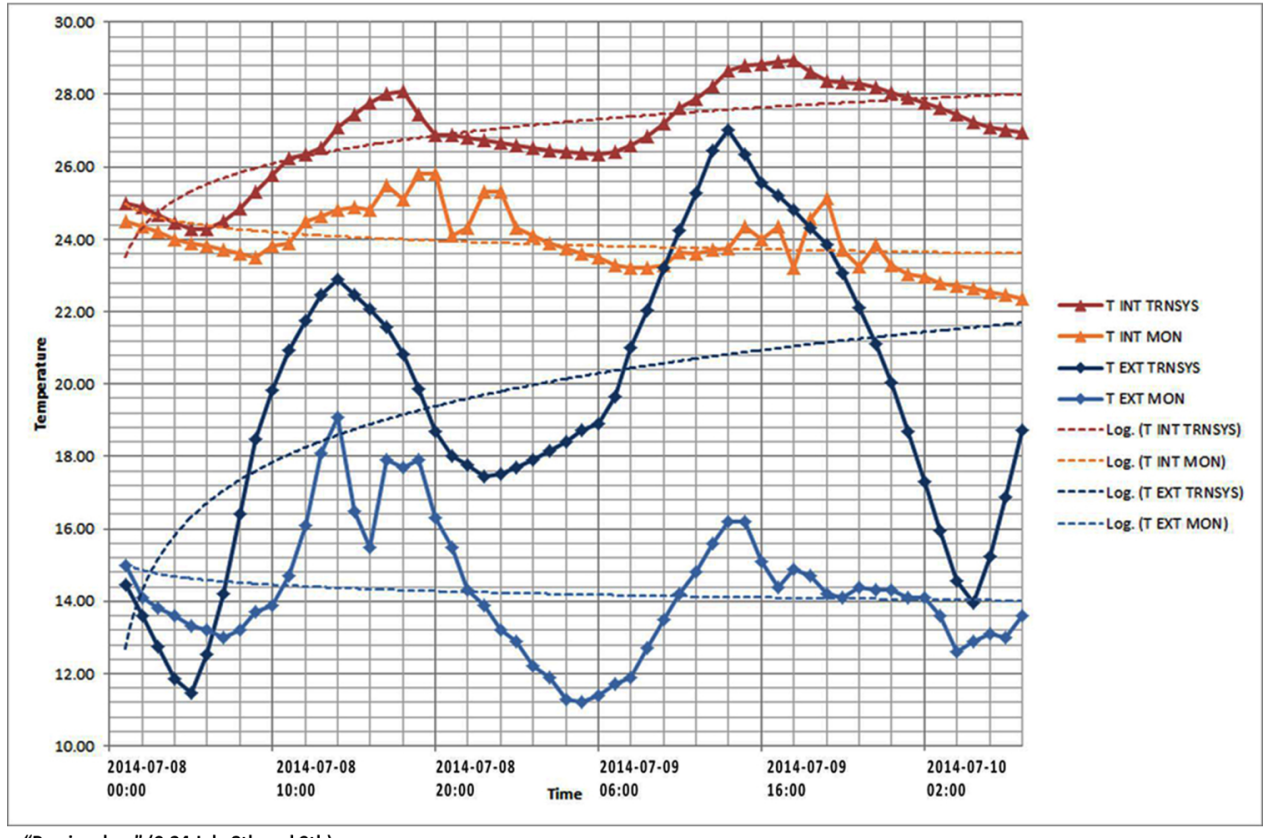

“Passive days" (0-24 July 8th and 9th):

Difference between simulation and monitored data in interior temperatures (top curves: red TRNSYS, orange monitored)

and exterior temperatures (dark blue TRNSYS, light blue monitored).

The diagram shows a similar time shift of interior temperatures, despite a difference in exterior temperatures.

Figure 15: "Passive days" (0-24 July 8th and 9th): Difference between simulation and monitored data in interior temperatures (top curves: red TRNSYS, orange monitored) and exterior temperatures (dark blue TRNSYS, light blue monitored). The diagram shows a similar time shift of interior temperatures, despite a difference in exterior temperatures.

- Insulation value on South Loggia with PV shading system closed (shaded window)

- No changes in weather file (so no "real conditions" experienced during real days)

Results and graphs are shown in Figure 14. The simulation showed that the temperature trend in the TRNSYS simulation is very similar to the ones measured in the prototype, despite a difference between the two in the values of exterior temperatures. In fact it is important to underline that, even if the competition was held in summer, there was an extraordinary weather condition with low temperatures and rainfall than seasonal averages. So the monitored exterior temperature is lower than the range of climatic file.

Obviously, the low transmittance of the envelope reduces temperature difference, and leaves a discrepancy of $4^{\circ} \mathrm{C}$ between simulation and monitored data, as shown in Figure 15.

It is important to highlight that a series of events during the competition caused significant peaks in temperature conditions. These events are not typical of daily residential use, but are linked to the competition, requiring some values to be changed according to score-based issues, or special openings of the house.
For example, at 8:00 PM on $8^{\text {th }}$ July, we opened all the windows for a $\mathrm{CO} 2$ change. And at 4:00 PM on $9^{\text {th }}$ July, a competition jury wished to see the house with all the windows open.

The graph in Figure 14 shows some temperature peaks of the monitored prototype that were not present in the simulation, since simulation was conducted without taking these occasional "special events" into account. Therefore, it has a more regular curve.

\section{DISCUSSION}

This research is still in progress-in different climates as well-but has so far provided an initial quantitative evaluation of the real contribution of mass to improve the summer passive thermal behaviour of lightweight envelopes, by working as thermal shock absorber. The intuition, supported by simulated trends appear to be confirmed by actual monitored performance.

The final aim of this work would be to make a definitive move from intuition to usable numerical data, and especially to the ability to quantify the amount of mass needed to obtain a certain numerical improvement in building performance. Sizing with an actual toolset [19] is not yet reliably possible. 
For this reason, our group plans to continue our investigation on mass behaviour in different climate conditions, but also in terms of overall layout and stratigraphy. Subsequent steps will also involve longterm prototype testing and the use of different dynamic simulation software platforms, seeking to overcome TRNSYS's limits in reproducing the distribution of internal temperatures, while still maintaining the same accuracy in system simulation and support in their design. In particular, we would like to use EDSL TAS Engineering, which allows hourly dynamic building simulation, taking into account the systems, building thermal performance and air flow of natural ventilation.

The team has begun a new prototype monitoring campaign in a different location from Versailles, whose monitoring data will be used to refine the design strategy, and will ultimately be made available to the scientific community following validation.

The study conducted on the relationship between monitored data and software simulation has confirmed how, in the presence of an intelligent design, software should not be assumed to replace design. Rather, it becomes a precious support for guiding validation of the design.

In this sense, all simplifications during simulation could be accepted or at least understood thanks to a design that knew what behaviour to expect.

Our work and initial results seem to confirm some of our intuitions, despite a different weather file and several minor differences in occupancy patterns and user behaviour. Still, it is also true that these parameters are difficult to anticipate fully.

This is a challenge in investigating the residential domain, where user contributions can have a significant impact on overall performance. It is not entirely clear how much these issues are worth anticipating.

In the current state of our work, we tried to use the opportunity of the Solar Decathlon as a fully monitored context, but had to consider the differences that it also imposes on "normal use" of a house:

\section{- A period of just two weeks of monitoring}

- Use of the house as a public building during part of the day

- A "score-based" approach to house performance, not always in line with daily use based on common sense
Therefore, further testing will have to be conducted on the re-built prototype, seeking to create a simulation model over a longer period and under similar context conditions, even if not fully in line with reality. Over a longer period, even these differences between simulated and monitored become smaller, another limitation of the small Solar Decathlon period.

\section{ACKNOWLEDGEMENT}

TRNSYS simulation was conducted with the precious help and tutoring of Emiliano Carnielo, Ph.D. from the ENEA Institute in Rome.

\section{REFERENCES}

[1] Givoni B. 1976. Man, Climate \& Architecture. 2nd Edition, Applied Science Publishers, Ltd., London, PP. 483.

[2] Kossecka, E., Kosny J., "Influence of insulation configuration on heating and cooling loads in a continuously used building", Energy and Buildings 34 (2002) 321-331. 206

[3] Zhou, J., Zhang, G., Lin, Y., Li, Y., "Coupling of thermal mass and natural ventilation in buildings", Energy and Buildings 40 (2008) 979-986.

[4] Source: Meteorological station "Roma Collegio Romano", located in the storic center of Rome. Data based on the latest 30-year climatic averages officially calculated for the meteorological observatory referring to the 1977-2006 period. T. min. average $\left({ }^{\circ} \mathrm{C}\right)$, mese di Gennaio $5,0^{\circ} \mathrm{C}$; T. max. average $\left({ }^{\circ} \mathrm{C}\right)$, mese di Luglio $30,7^{\circ} \mathrm{C}$

[5] Ogoli, D.M., "Predicting indoor temperatures in closed buildings with high thermal mass", Energy and Buildings 35 (2003) 851-862.

[6] Willoughby, J., Using thermal mass to save energy in housing, The Structural Engineer, June 2002; 80(12), 11 13

[7] Yang, L., Li, Y., (2008), "Cooling Load Reduction By Using Thermal Mass \& Night Ventilation", Energy and Buildings, Volume 40, Issue 11, 2008, Pages 2052-2058

[8] Evangelisti, L., Guattari, C., Gori,P., De Lieto Vollaro, R., Asdrubali, F., "Experimental investigation of the influence of convective and radiative heat transfers on thermal transmittance measurements", International Communications in Heat and Mass Transfer (2016) 78, 214-223;

[9] Lund, P.D., "Optimum Solar House - Interplay Between Solar Aperture and Energy Storage", Proceedings of the ISES Solar World Conference, Budapest, August 23 - 27, 1993, 105-111,

[10] Tonelli, C., Grimaudo, M., Energy and Buildings, "Timber buildings and thermal inertia: open scientific problems for Summer behavior in Mediterranean climate.", 2014, vol. ENB4834, ENB-D-13-01558, ISSN: 0378-7788, doi: 10.1016/j.enbuild.2013.12.063

[11] Barnard, N., Concannon, P., Jaunzens, D., "Modelling the Thermal performance of thermal mass", IP6/01, Building Research Establishment, UK, April 2001.

[12] Munaretto, F., Peuportier, B., Guiavarch, A., Building Simulation Conference 2013, "Accounting for thermal mass in thermal simulation tools: comparison of several.", 2009, http://www.ibpsa.org/proceedings/BS2013/p_1266.pdf

[13] Pernigotto, G., Gasparella, A., HVAC\&R Research, "Extensive comparative analysis of building energy simulation codes: Heating and cooling energy needs and peak loads calculation in TRNSYS and EnergyPlus for 
southern Europe climates.", 2013, n 19,481-492 doi: 10.1080/10789669.2013.794088.

[14] Mithraratne, P., Vale, B., "Behaviour of Thermal Mass in Passive Solar Houses", Proceedings of the 41st ANZES Destination Renewable Conference, University of Melbourne, Australia, November 26 - 29, 2003.

[15] Caputo, P., Ferrari, S., Costa, G., Web Research Report, Milan Polytechnic, Milan Italy, "Analisi del comportamento energetico di edifici monozona. Comparazione tra gli strumenti Odesse, TRNSYS ed Energy Plus", 2010, http://www.enea.it/it/Ricerca_sviluppo/documenti/ricerca-disistema-elettrico/tecnologie-riduzione-consumi/10reportcaputo-polimi.pdf

[16] Brun, A., Spitz, C., Wurtz, E., Mora, L., Conference Proceedings Building Simulation Conference 2009. "Behavioural comparison of some predictive tools used in a low-energy building", 2009, http://www.ibpsa.org/ proceedings/BS2009/BS09_1185_1190.pdf

[17] Zhang, Y., Zhou, G., Lin, K., Zhang, Q., Di H. (2007), "Application of latent heat thermal energy storage in buildings: State-of-the-art and outlook", Building and Environment, vol. 42, pp. 2197- 2209

[18] UNI EN 15251:2007 "Indoor environmental input parameters for design and assessment of energy performance of buildings- addressing indoor air quality, thermal environment, lighting and acoustics"

[19] Crawleya, D.B., Lawrieb, L.K., Winkelmannc, F.C., Buhlc, W.F., Huangc, Y.J., Pedersend, C.O. Strandd, R.K.., Liesend, R.J., Fishere, D.E., Wittef, M.J., Glazerf, J., Energy and Buildings, "EnergyPlus: creating a new-generation building energy simulation program.", 2001, n 33, 319-331. https://doi.org/10.1016/S0378-7788(00)00114-6

(c) 2017 Fabrizio Tucci; Licensee Lifescience Global.

This is an open access article licensed under the terms of the Creative Commons Attribution Non-Commercial License (http://creativecommons.org/licenses/by-nc/3.0/) which permits unrestricted, non-commercial use, distribution and reproduction in any medium, provided the work is properly cited. 